\title{
ELEIÇÕES, MESÁRIOS E SUBJETIVIDADE: REFLEXÕES SOBRE A PRODUÇÃO DE SENTIDOS SUBJETIVOS A PARTIR DA PARTICIPAÇÃO VOLUNTÁRIA NO PROCESSO DE VOTAÇÃO ELECTIONS, POLL WORKERS AND SUBJECTIVITY: REFLECTIONS ON THE PRODUCTION OF SUBJECTIVE SENSE FROM THE VOLUNTARY PARTICIPATION IN THE PROCESS OF VOTING
}

\author{
Aigline de Menezes Paes Vervloet e Márcia Prezotti Palassi \\ Universidade Federal do Espírito Santo, Vitória, Brasil
}

\begin{abstract}
RESUMO
Apesar dos avanços no processo eleitoral brasileiro e do aumento de mesários voluntários, erros e comportamentos inadequados, que embaraçam ou impedem o exercício do voto, continuam ocorrendo. De modo a estabelecer uma reflexão que contribua para a melhor compreensão do problema, propôs-se analisar os sentidos subjetivos que emergem frente à participação desses voluntários. Adotou-se como marco teórico, epistemológico e metodológico, a Teoria Histórico-Cultural da Subjetividade, de González Rey. A pesquisa, além de bibliográfica e documental, é um estudo de caso. Os instrumentos utilizados foram questionário aberto, construção de frases, redação e conversações. Participaram deste estudo onze mesários, que atuaram nas eleições de 2008, na 55 Zona Eleitoral/ ES. Os sentidos identificados relacionam-se a sentimentos de descrédito, desejo de mudança social, obrigação moral/social, satisfação pessoal e benefícios particulares. Conclui-se que os sentidos subjetivos interferem no comportamento durante a participação voluntária, sugerindo necessidade de adequações na gestão do processo.
\end{abstract}

Palavras-chave: subjetividade; sentidos subjetivos; participação voluntária; mesários; eleições.

\begin{abstract}
Despite advances in Brazilian electoral process and increase of poll workers, errors and inappropriate behaviors that hinder or impede the exercise of voting rights continue to occur. In order to establish a reflection that will help in better understanding the problem, we proposed to analyze the subjective meanings that emerge opposite the participation of these volunteers. We adopted as theoretical, epistemological and methodological background the Historic-Cultural Theory of Subjectivity, by González Rey. The methods used were open questionnaire, sentence construction, writing and conversations. This study included eleven poll workers, who participated in the 2008 elections, in the 55th Electoral Zone / ES. The meanings identified relate to feelings of distrust, desire for social change, moral / social obligation, personal satisfaction and private benefits. We concluded that the subjective senses interfere in the poll workers behavior during voluntary participation, suggesting the need for adjustments in the process management.
\end{abstract}

Keywords: subjectivity; subjective senses; voluntary participation; poll workers; elections.

\section{Introdução}

No Brasil, a tradição da prática eleitoral é longa, quase tão antiga quanto o próprio país. Contudo, o eleitorado brasileiro nem sempre foi numeroso, nem a competitividade e confiabilidade do processo eleitoral garantidas, muito pelo contrário, diversos tipos de restrição ao voto, de violência, fraude, manipulação e interferência do poder privado no domínio público fizeram parte de sua história, contribuindo para a realização de pleitos ilegítimos.
Desde o período colonial observa-se a insuficiência do poder público no Brasil, especialmente, naquela época, diante das dificuldades geradas por sua extensa área territorial. $\mathrm{O}$ isolamento e a pobreza de boa parte da população motivavam uma relação de grande dependência dos trabalhadores em relação aos proprietários de terras, que, não raras vezes, assumiam o papel de "representantes do estado e do poder" (Acioli, 1997).

Nesse ambiente faltava instrução, segurança, livre-arbítrio e, principalmente, qualquer noção do que fosse um governo representativo ou do que significava 
o ato de escolher alguém como seu representante político (Leal, 1997). O voto era um ato de obediência, de lealdade ou gratidão. Passando, mais tarde, a ser considerado também como uma mercadoria, a ser vendida pelo melhor preço (Carvalho, 2006).

Com a aprovação do Código Eleitoral, em 24 de fevereiro de 1932, mudanças significativas foram implementadas no cenário político brasileiro, dentre as quais se destacam a criação da Justiça Eleitoral; a ampliação do eleitorado, por meio da inclusão do voto feminino e da redução do limite de idade para 18 anos; e a instituição do voto secreto, garantindo o sigilo do sufrágio.

Em 1934, com a promulgação da segunda Constituição republicana, todos esses avanços foram transplantados para o elenco constitucional, fortalecendo a estrutura da democracia e o respeito à cidadania. Entretanto, sua existência foi efêmera, perdurando por menos de quatro anos, em razão do golpe que instaurou o Estado Novo, em 10 de novembro 1937 (Leal, 1997).

A reimplantação da Justiça Eleitoral se deu através do Decreto 7.586, de 1945 (Acioli, 1997; Carvalho, 2006). Nas eleições de 1945, 1950, 1954 e 1958 os eleitores votavam utilizando cédulas já preenchidas, que eram ofertadas pelos próprios partidos concorrentes. A primeira vez a se utilizar a cédula oficial, fornecida pela Justiça Eleitoral, foi nas eleições presidenciais de 1955. Desde então, o eleitor passou a escrever o nome e/ou o número de seu candidato ou partido (Nicolau, 2004).

Em 1964 o país passou por outro golpe empreendido pelos militares; período que ficou marcado, além das torturas e arbitrariedades cometidas, pela falta de competitividade dos pleitos, provocada pela implantação do bipartidarismo compulsório - Arena e MDB.

No entanto, apesar de toda a temática de restrições nas liberdades, ... a Justiça Eleitoral não teve suas funções institucionais alteradas, e foi justamente devido à sua permanência e atividade durante o período castrense, mesmo que atuando sobre um sistema de eleições indiretas, mas com calendário eleitoral fixo, que foi possível à população, nas urnas, demonstrar sua indignação e seu repúdio para com o regime em descrédito. (Valente Neto, 2004, p. 87)

Nos dias de hoje, no que concerne à independência da administração do processo eleitoral, o Brasil atingiu um estágio bastante maduro, baseado em um modelo institucional consolidado e em técnicas modernas que garantem eficiência e lisura (Sadek, 1995), indiscutivelmente capazes de diluir práticas condenáveis da nossa história política (Lima, 2005).

Porém, ainda não há evidências de uma aproximação efetiva entre o povo e as decisões políticas, nem mesmo com a eleição de representantes dos segmentos que reclamavam a participação popular no cenário político: "o fato é que esse povo assiste atônito aos pactos conservadores das elites que negam constantemente os direitos elementares da maioria" (Iasulaitis \& Silva, 2006, p. 3).

Nesse sentido, Valente Neto (2004) nos leva a refletir que, apesar dos importantes avanços, não se pode esquecer que algumas mazelas, decorrentes de fatores econômicos e sociais, persistem e têm contribuído para obstacularizar o desenvolvimento da democracia e o aprimoramento moral, técnico e material das instituições políticas e públicas.

Assim, se por um lado a organização e confiabilidade das eleições, o livre funcionamento dos partidos políticos e a normalidade institucional são louváveis, noutro polo o poder econômico tem demonstrado que uma democracia que garanta uma razoável igualdade nas disputas eleitorais ainda é irreal no Brasil. O financiamento das campanhas por particulares e a compra de votos são exemplos de artifícios resultantes do abuso do poder econômico, ainda bastante difundidas no contexto brasileiro (Lima, 2005; Speck, 2003).

Percebe-se que, no Brasil, a democracia moderna não foi capaz de romper por completo com as práticas políticas do passado. A legislação evoluiu, os atores foram substituídos e, por sua vez, os métodos clientelistas e patrimonialistas se aprimoraram, adaptando-se à nova realidade, evidenciando sua coexistência em meio aos mecanismos burocráticos atuais (Lima, 2005; Vasconcelos, 1995).

Existe um jogo duplo na política brasileira, em que o discurso público se refere aos direitos e necessidades dos cidadãos do país; porém, o que impulsiona o cotidiano da sociedade é uma prática política que se rege pela lealdade das relações pessoais, desvinculada de qualquer compromisso legal ou ideológico. (Shimizu \& Menin, 2004, p. 11).

De qualquer modo, não há como negar que um dos instrumentos mais importantes para o controle do poder político é o voto, e que esse dispositivo democrático é bastante respeitado no Brasil. Sabucedo (1996) menciona que estudos realizados em diferentes países demonstram que a participação eleitoral exerce papel fundamental nos sistemas democráticos, além de ser a via mais usual para a manifestação dos cidadãos.

Nesse sentido, destaca-se o papel desempenhado pelos mesários nas eleições, visto que são eles quem, após meses de planejamento e intenso trabalho da Justiça Eleitoral, efetivamente a representam perante os eleitores. Conforme dispõe o Código Eleitoral de 1965 (Tribunal Superior Eleitoral, 2008, pp. 77-79):

Art. 120. Constituem a Mesa Receptora um Presidente, um Primeiro e um Segundo Mesários, dois Secretários e um suplente, nomeados pelo Juiz Eleitoral sessenta dias antes da eleição, em audiência pública, anunciada pelo menos com cinco dias de antecedência ... 
Art. 124. O membro da Mesa Receptora que não comparecer no local, em dia e hora determinados para a realização de eleição, sem justa causa apresentada ao Juiz Eleitoral, até 30 (trinta) dias após, incorrerá na multa ...

Essa nomeação, na forma como é prevista em lei, prescinde da vontade dos indivíduos selecionados e recai sobre os denominados "mesários convocados", e assim vem sendo aplicada em grande parte das Zonas Eleitorais. Entretanto, o Cartório Eleitoral da 55 ${ }^{\mathrm{a}}$ Zona/ES deu início, em 1997, a uma campanha de incentivo à participação voluntária dos cidadãos no processo de votação.

Os motivos para a realização dessa campanha, bem como para sua continuidade, foram aumentar a qualidade dos serviços prestados aos eleitores e facilitar a localização dos mesários nomeados, visto que na eleição anterior (1996) ocorreram muitas reclamações e erros em decorrência da má atuação de mesários, além das dificuldades relativas à localização dos mesmos com base no endereço constante no cadastro eleitoral, muitas vezes desatualizado. Diante disso, a proporção de mesários voluntários foi tornando-se mais significativa a cada eleição, chegando, em 2008, a 100\% do total dos nomeados para as seções de votação da $55^{\mathrm{a}}$ Zona/ES.

Vale esclarecer que, tendo como referência os trabalhos inerentes à localização dos mesários e ao preenchimento das seções de votação, a participação de voluntários tem se mostrado de grande valia, provendo os servidores da Justiça Eleitoral de melhores condições para a realização dos mesmos. Já quanto à qualidade do atendimento ao público, não mostrou resultado plenamente satisfatório, visto que ações inadequadas continuam ocorrendo. Não são raras situações em que um eleitor é "autorizado", por equívoco do mesário, a votar em lugar de outro; em que mesários recebem o auxílio alimentação e não retornam após o almoço; mesários que se recusam a cooperar com os trabalhos; que se ausentam com frequência da seção; que "destratam" os eleitores; que não aceitam que os idosos e deficientes físicos tenham preferência para votar; que trabalham alcoolizados; que promovem ou permitem "boca de urna" na seção; dentre outras.

É responsabilidade dos mesários manusear a urna eletrônica, prepará-la para receber o voto, zelar pela indevassabilidade da cabina, identificar e orientar os eleitores e fiscalizar a lisura do processo eleitoral na respectiva seção. Através do mesário, o povo fiscaliza e constrói todo o processo eleitoral, validando a ação da Justiça Eleitoral.

Dessa forma, procurando desvendar aspectos associados à diversidade humana que possam estar interferindo no exercício da função, propomos esta pesquisa, sob a ótica da Teoria Histórico-Cultural da
Subjetividade, desenvolvida por González Rey, a partir de 1997. Buscou-se, mais especificamente, a partir da identificação e análise dos sentidos subjetivos que emergem frente à participação dos mesários voluntários nas eleições, confrontar os resultados efetivos dessa participação, estabelecer uma reflexão que possa contribuir para a compreensão dos fatores que poderiam estar colaborando para a ocorrência de ações inadequadas de mesários durante as eleições, bem como para o aprimoramento das práticas de gestão da Justiça Eleitoral envolvidas no processo de votação.

Para desenvolver essa abordagem, nos próximos tópicos do artigo discute-se o tema da subjetividade, sob o enfoque histórico-cultural, e resgata-se a temática da participação voluntária. Em seguida, apresenta-se a metodologia adotada na pesquisa e a análise dos resultados obtidos no estudo de caso realizado na $55^{\text {a }}$ Zona Eleitoral do Estado Espírito Santo. Por fim, são feitas as considerações finais, seguidas das referências.

\section{A subjetividade na perspectiva histórico- cultural}

A Teoria da Subjetividade tem como principal objetivo dar visibilidade às complexas formas através das quais se expressa o psiquismo humano, compreendidas como resultado de um intrincado processo que envolve a história particular do sujeito e a dimensão histórica e cultural relacionadas ao seu ambiente de inserção (Furtado, 2002; Martinéz, 2005).

Ressalta-se que a compreensão da subjetividade dentro dessa proposta pressupõe a superação de toda forma reducionista e simplificadora de representação da psique, a qual não pode ser restrita aos níveis biológico e cultural da existência humana. Bock \& Gonçalves (2005) destacam que é justamente a dialética entre o constitutivo (história do sujeito resultante de fatores culturais, biológicos e ontogenéticos) e o construído (derivado dos processos de construção e reconstrução do sujeito diante das situações vivenciadas) que torna possível a constituição da subjetividade. De tal modo que "o sujeito não se constitui independentemente do contexto onde está inserido, mas também não é mero produto do meio social" (Amaral, 2006, p. 29).

Dessa forma, foge-se a qualquer compreensão determinista do ser humano, provocando-se, ainda, a ruptura de dicotomias clássicas, como indivíduo-sociedade, cognitivo-afetivo, objetivo-subjetivo, conscienteinconsciente, entre outras, concebendo os processos subjetivos em meio às múltiplas dimensões que se viam como excludentes (Martínez \& Simão, 2004).

Enfatizando a complexa integração entre o social e o individual, como a característica da subjetividade 
que a torna capaz de admitir a flexibilidade dos processos de produção de sentidos e significados numa determinada cultura, González Rey (2003, p. IX) concebe a subjetividade como "um complexo e plurideterminado sistema, afetado pelo próprio curso da sociedade e das pessoas que a constituem dentro do contínuo movimento das complexas redes de relações que caracterizam o desenvolvimento social". Lembrando que a condição de sujeito individual só se concretiza nos diferentes espaços sociais em que o homem vive e opera, do mesmo modo que o mundo social é produto da coletividade, no sentido que é construído subjetivamente pelos sujeitos ou grupos que a compõem ou dela já foram parte.

A subjetividade social é, portanto, o espaço social subjetivado, no qual o sujeito atua de forma processual e permanente, sujeito esse que representa um ponto de confluência entre as subjetividades social e individual (González Rey, 2002). Assim, a partir da perspectiva histórico-cultural, torna-se impossível pensar a subjetividade separada do sujeito, pois é através dele e no decorrer de seus processos de socialização, que uma ação adquire sentido subjetivo.

González Rey (2003, 2004, 2005) esclarece, ainda, que a subjetividade não pode ser vista como um sistema racional, controlável e previsível, pois sua organização e desenvolvimento não estão subordinados à razão humana, embora por ela sejam influenciados. Assim, as posições racionais dos indivíduos devem ser entendidas como "produções de sentido", na medida em que se organizam sobre seus interesses, emoções e necessidades, relacionadas aos contextos onde são produzidas, e a partir de sua história de vida particular.

Nesse sentido, afirma: "a razão está subordinada a uma produção histórica de sentidos e não ao contrário" (González Rey, 2004, p.131). Desse modo, o sujeito se constitui e se modifica por meio de configurações subjetivas de que não tem consciência, ao mesmo tempo em que produz, de forma consciente, novos processos de subjetivação, através de suas ações, projetos, reflexões e representações, cujas consequências vão muito além dos resultados intencionalmente pretendidos, o que torna a categoria sujeito a peça-chave para se entender os processos de constituição subjetiva e de desenvolvimento, tanto individuais como sociais (González Rey, 2003, 2004).

O sentido subjetivo representa, então, a forma essencial dos processos de subjetivação, uma vez que exprime as diferentes formas de apreensão da realidade que, por meio de complexas unidades simbólicoemocionais, são constituídas a partir das histórias dos sujeitos e dos contextos culturais e sociais nos quais está sendo produzido, ou seja, aparece como registro emocional único, comprometido com os significados e as necessidades desenvolvidos no decorrer da vida do sujeito (González Rey, 2002, 2003, 2005).
Destaca-se que essa "rota singular" de produção de sentidos não é cristalizada, imutável ou linear, uma vez que, a cada nova experiência vivenciada pelo sujeito, novos sentidos serão constituídos e integrados ou não à sua configuração subjetiva anterior, confirmando as posições adotadas ou gerando uma nova configuração subjetiva, capaz de suscitar outras possibilidades de ação. Portanto, a categoria sentido subjetivo é capaz de integrar as experiências psicológicas antigas e atuais do sujeito, de forma a revelar uma nova configuração subjetiva que dê suporte a sua realidade presente (González Rey, 2003, 2004, 2005).

Como bem ilustra Amaral (2006), a existência humana é indiscutivelmente marcada por um processo ininterrupto de produção de sentidos, "que funciona como um colorido especial que cada um dá para a própria vida e que se converte em um impulso para o desenvolvimento de projetos pessoais" (Amaral, 2006, p. 41).

Diante do exposto, compreende-se que a participação voluntária pode ser entendida como uma trama de sentidos subjetivos, levando-se em consideração a multiplicidade de fatores que nela e dela efetivamente resultam.

\section{Participação e voluntariado: visões sobre a participação voluntária}

Segundo Demo (1993) e Sabucedo (1996), participação é um conceito que está obrigatoriamente unido ao de democracia, visto que a essência de um regime democrático está na possibilidade que os cidadãos têm de influir no curso das decisões e acontecimentos políticos, sendo parte ativa no curso da sociedade. Bordenave (1994) acrescenta que, quando a população participa da implementação e fiscalização dos serviços públicos, estes tendem a melhorar em qualidade e eficácia, além de tornarem-se mais adequados às suas verdadeiras necessidades. Nesse sentido, conclui-se que, através da participação, a sociedade transforma o Estado, de órgão superposto e distante dela, em órgão dependente e próximo a ela, já que o povo passa a exercer o controle final das decisões, sendo o real detentor do poder.

A palavra participar deriva do latim participare, que significa “ter ou tomar parte". Enquanto voluntário, palavra também originada do latim, deriva de voluntariu e expressa "aquele que age espontaneamente" (Instituto Antônio Houaiss, 2001). Assim, participação voluntária pode bem exprimir fazer parte, tomar parte ou ter parte, por vontade própria, num grupo e/ou numa atividade.

Para Garay (2001) e Souza, Fernandes e Medeiros (2006), a ação voluntária é profundamente vinculada a termos como cidadania, responsabilidade social e transformação social, justificando sua importância nos dias 
de hoje, em face da insatisfação e de angústias gerais. Sendo, ainda, muito associada a valores religiosos, de caridade e assistencialismo. Reforçando essa ideia, Teodósio, Veneroso \& Pena (2006) afirmam que, não raras vezes, o voluntário é, automaticamente, compreendido como alguém solidário, fraterno e abnegado. Tal concepção é proveniente da perspectiva histórica da prática voluntária, ligada à Igreja Católica e baseada na caridade, na compaixão, no altruísmo e na doação (Silva, 2006, citado por Dias \& Palassi, 2007).

Nessa esteira, Smith (1981, citado por Mascarenhas \& Zambaldi, 2002) defende que há uma tendência social de valorizar o altruísmo e condenar o uso de atividades desse tipo com "objetivos egoístas", do tipo posicionamento social, diversão e socialização. Por isso, os motivos altruístas são tão dominantes no discurso dos voluntários sobre si mesmos. Entretanto, ressalta que não se trata de dizer que os voluntários não estejam interessados em ajudar aos outros, mas sim que os motivos altruístas não são incompatíveis com os motivos egoístas, podendo coexistir na participação voluntária.

Reforçando essa ideia, o estudo de Souza, Fernandes e Medeiros (2006) demonstra que o trabalho voluntário congrega categorias de motivos altruístas, de interesse próprio e de sociabilidade, mediados por ideais religiosos, afetivos ou aflitivos, resultantes de sentimentos de culpa ou de obrigação para com o outro ou de sentimentos de responsabilidade.

Constatação semelhante foi obtida em pesquisa realizada por Vervloet (2008), quando analisou os motivos relatados pelos mesários voluntários para sua participação nas eleições, os quais sempre combinavam motivações de origem pessoal e social, demonstrando que servir em benefício de outras pessoas não os tornava imunes aos possíveis retornos que poderiam advir, direta ou indiretamente, do voluntariado.

Não obstante, há de se observar que a participação voluntária não pode ser analisada somente como sendo um instrumento para a solução de problemas. Mas, sobretudo, como um direito fundamental do ser humano, inerente à sua natureza social. Visto que, por meio dela, são satisfeitas diversas necessidades humanas, tais como: pensamento reflexivo, valorização de si mesmo pelos outros, expressão e interação.

Assim, independente de ser motivada por interesses próprios e/ou por solidariedade, a atuação voluntária permite contribuir tanto para o atendimento das necessidades da comunidade quanto para as necessidades dos próprios voluntários, na medida em que promovem autorrealização, fortalecem a identidade, aumentam a autoestima e desenvolvem espírito crítico (Garay, 2001).

Dessa forma, pode-se afirmar que a participação voluntária é capaz de adquirir múltiplos sentidos e sig- nificados, que dependem da relação que se estabelece no contexto onde ela ocorre e, principalmente, do que o indivíduo busca na atividade para a qual se voluntaria e na sua própria vida (Dias \& Palassi, 2007; Garay, 2001). Reforça, assim, a ideia de que o vínculo estabelecido entre o voluntário e as ações ou projetos dos quais participa é muldimensional e fortemente associado a características contextuais e disposições pessoais.

\section{Procedimentos metodológicos}

A pesquisa delimitou-se à $55^{\mathrm{a}}$ Zona do Tribunal Regional Eleitoral do Espírito Santo - TRE/ES, em específico, à participação dos mesários voluntários que atuaram durante as eleições do ano de 2008, no município de Vila Velha/ES.

Vale esclarecer que, dentre os diversos cartórios eleitorais do Estado do Espírito Santo, elegeu-se a 55 Zona Eleitoral para a realização desta pesquisa, considerando seu pioneirismo na realização de campanha de incentivo à participação de mesários voluntários e sua expressiva abrangência, sendo responsável pela administração do assentamento eleitoral e pelo voto de 141.710 eleitores, residentes em 54 bairros.

A pesquisa, além de bibliográfica e documental, é um estudo de caso. Adotou-se o método de estudo de caso, por acreditarmos, tal como González Rey (1999), que através desse método a produção teórica tem a possibilidade de expressar a permanente tensão entre o individual e o social, representando, então, um "momento essencial para a produção de conhecimentos sobre ambos os níveis de construção da subjetividade" (González Rey, 1999, p. 158).

Participaram da pesquisa 11 sujeitos, sendo 8 homens e 3 mulheres. Quanto à idade, o grupo abrange diferentes faixas etárias, entre 18 e 61 anos. Quanto à escolaridade, 1 participante possui $1^{\circ}$ grau do ensino fundamental; 5 participantes possuem o $2^{\circ}$ grau do ensino médio ou técnico; 3 curso superior completo e 2 são pós-graduados. Quanto à ocupação dos participantes, verifica-se que apenas 1 é exclusivamente estudante, sendo que todos os demais, inclusive os já aposentados, exercem atividades laborais, sendo 4 deles servidores públicos, 4 trabalhadores de organizações privadas e 2 autônomos.

O presente estudo foi orientado pelo modelo qualitativo de pesquisa, fundamentando-se na epistemologia qualitativa desenvolvida por González Rey (1997), que compreende a pesquisa científica como um processo de construção teórica do pesquisador, e não como uma apropriação linear da realidade (González Rey, 2005). Construção essa que privilegia a ação, a flexibilidade e o pensamento criativo, constituindose num processo de diálogo e reflexão conjunta, em 
que a legitimidade do conhecimento está associada ao desenvolvimento progressivo de zonas de sentido em relação ao problema estudado e não à comprovação e verificação de uma dada realidade.

Como zona de sentido, González Rey (2003, 2005 ) entende a criação de um novo espaço de significação sobre um campo ou objeto de estudo, capaz de viabilizar a continuidade do pensamento humano, possibilitando novas zonas de ação sobre a realidade e novos caminhos dentro dela. Portanto, o que se pretende é aumentar a capacidade de aproximação e compreensão acerca do objeto estudado.

De acordo com essa visão, as informações foram obtidas durante seis momentos empíricos vivenciados entre os meses de agosto e novembro de 2008, a seguir descritos:

$1^{\circ}$ momento: apresentação da pesquisa, seguida de conversação e aplicação de questionário aberto, envolvendo, individualmente, cada um dos participantes - visando a inserção do sujeito no contexto da pesquisa e o levantamento dos primeiros indicadores de sentidos subjetivos.

$2^{\circ}$ momento: proposta de construção de frases, seguida de conversação individual com cada sujeito.

$3^{\circ}$ momento: conversação grupal, com todos os sujeitos da pesquisa, possibilitando que, de forma interativa, fossem expressos e/ou demonstrados sentimentos, concepções, representações, simbologias e emoções que guardassem relação, direta ou indireta, com o tema pesquisado.

$4^{\circ}$ momento: observação durante os treinamentos da Justiça Eleitoral, procurando interpretar, inter-relacionar e confrontar as informações obtidas nos momentos anteriores, diante das manifestações e comportamentos dos participantes.

$5^{\circ}$ momento: observação dos sujeitos nas eleições ( $1^{\circ}$ e $2^{\circ}$ turno de votação), quando, ainda, solicitou-se a elaboração de uma redação: "Eu nas eleições 2008".

$6^{\circ}$ momento: análise dos documentos provenientes das seções e locais de votação, tais como: atas, relatórios e formulários, relacionados aos comportamentos inadequados e problemas ocorridos, bem como às situações envolvendo os mesários participantes da pesquisa.

Ressalta-se que todas as observações e imprevistos ocorridos foram devidamente registrados em um diário de campo, o qual contribuiu imensamente para a construção do conhecimento emergente desta pesquisa.

Observa-se que, conforme recomenda González Rey $(2002,2005)$, as informações obtidas durante a parte empírica deste estudo foram advindas de momentos e situações bastante distintos, oferecendo às pesquisadoras diferentes possibilidades de reflexão e confrontação entre as próprias informações e o modelo teórico que foi sendo construído (e reconstruído) durante a pesquisa, possibilitando, ainda, uma melhor compreensão a respeito dos sujeitos.

Coerente com essa perspectiva, González Rey (2005) propõe que as informações obtidas são suscetíveis de múltiplas opções de análise e organização, dependendo-se unicamente do problema e dos propósitos da pesquisa. Entretanto, o autor faz algumas recomendações, que precisam ser, necessariamente, observadas pelo pesquisador, conforme se seguem:

- Os agrupamentos devem organizar e produzir significados, não ficando restritos apenas ao conteúdo explícito das expressões dos sujeitos, permitindo a construção de hipóteses;

- $\quad$ Podem ser usadas tabelas, comparações e outros recursos para a interpretação dos dados em nível macro, desde que permitam a análise dos elementos da subjetividade social e individual que estejam por de trás e além dos dados concretos;

- Os sujeitos estudados devem ser vistos como produtores de experiência e não como respostas pontuais;

- Os indicadores obtidos através de um instrumento, aplicado a determinado sujeito, devem ser necessariamente relacionados e integrados a outros indicadores, provenientes de diferentes momentos da pesquisa e da expressão de outros sujeitos participantes, permitindo a definição de núcleos de sentido mais amplos;

Os momentos de informalidade e as situações não previstas que venham a ocorrer durante o processo de pesquisa também são considerados como fonte de indicadores, pois a partir deles podem emergir informações significativas para a compreensão do problema.

- Um modelo teórico nunca é algo acabado, pois, tal como a subjetividade, está em constante processo de transformação, e ainda admite formas diferenciadas de construção e apresentação, sem que nenhuma delas possa ser considerada mais válida ou correta, pois cada pesquisador conduzirá, organizará e interpretará as informações do modo como julgar mais coerente e adequado aos seus propósitos.

Diante dessas considerações, criamos um fluxograma (Figura 01), com o intuito de representar, de forma sintetizada, o caminho seguido para a organização das informações, análises e construção do conhecimento: 
Figura 1 - Fluxo da análise e construção do conhecimento.

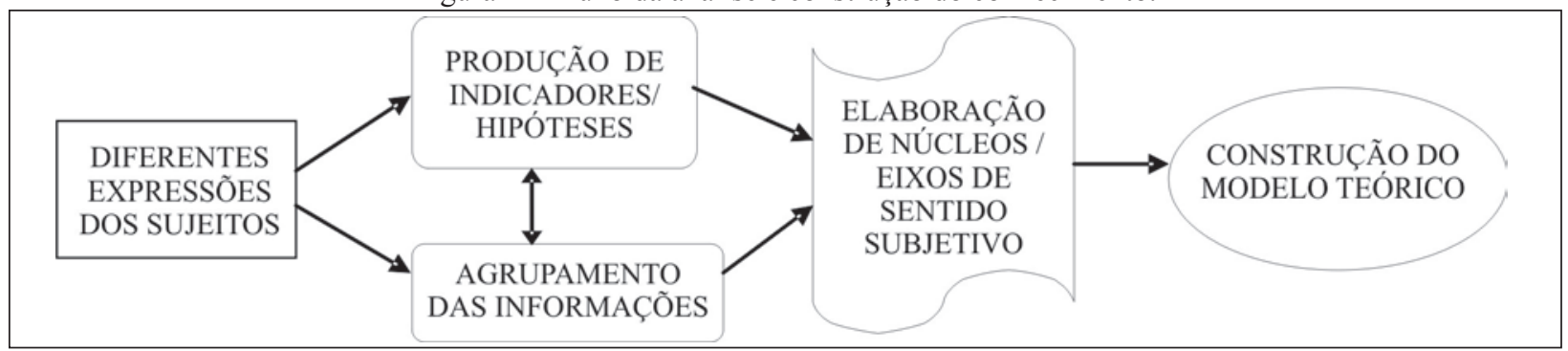

Fonte: Elaborado pelas autoras, com base em González Rey (1997, 2002, 2005).

Dessa forma, organizando as manifestações dos sujeitos a partir da interpretação de seus significados dentro do contexto de sua produção e não simplesmente por seu conteúdo explícito e relacionando-as aos indicadores/hipóteses levantados em outros momentos empíricos e teóricos da pesquisa, nosso foco foi desenvolver um "modelo teórico" deste estudo, que proporcionasse uma maior compreensão acerca dos múltiplos sentidos subjetivos que a participação voluntária do mesário nas eleições pode assumir nos indivíduos que a vivenciam, bem como os possíveis resultados das ações e reações que tais sentidos podem vir a propiciar no decorrer da efetiva realização das atividades dos mesários pesquisados.

A fim de garantir o anonimato dos participantes, utilizou-se durante a análise e discussão das informações, um nome fictício para a identificação de cada sujeito pesquisado.

Utilizaram-se, ainda, as seguintes siglas para indicar a partir de qual instrumento os trechos de informação foram obtidos: QD - Questionário Diagnóstico; CF Construção de Frases; CI - Conversação Individual; CG - Conversação Grupal; R - Redação.

\section{Resultados: análise e discussão}

Os sentidos subjetivos apreendidos, a partir de cada sujeito desta pesquisa, revelam o quanto a produção subjetiva dos mesários voluntários é influenciada pela conjuntura histórica, política e social do nosso país. $\mathrm{O}$ que se torna evidente, de maneira especial, nas relações por eles estabelecidas entre eleições/atuação do mesário e sentimentos de descrédito, revolta, impotência, desânimo, esperança e desejo de mudança social. Ademais, observa-se grande quantidade de sentidos subjetivos relacionados à satisfação pessoal e aos benefícios particulares decorrentes desta forma de participação voluntária, os quais, em sua maioria, interferem positivamente na atuação desses voluntários, além de funcionarem como estímulo para a participação no projeto.

Ressalta-se que, tendo em vista a limitação de páginas de um artigo, torna-se inviável que todos os momentos vivenciados por cada sujeito durante a pesquisa, bem como os indicadores e hipóteses levantados no decorrer das análises realizadas, sejam aqui explicitados de maneira mais densa. Assim sendo, apresenta-se no Quadro 1, a seguir, uma breve descrição acerca dos sujeitos investigados, bem como os principais sentidos subjetivos que caracterizam a participação de cada um deles como mesário voluntário.

Quadro 1: Caracterização dos sujeitos participantes e síntese dos sentidos subjetivos relacionados à participação de cada um deles.

\begin{tabular}{|c|c|c|}
\hline MESÁRIO & CARACTERIZAÇÃO & SENTIDOS SUBJETIVOS \\
\hline $\begin{array}{l}\text { TEREZA } \\
\text { (5ª vez como } \\
\text { mesário } \\
\text { voluntário })\end{array}$ & $\begin{array}{l}\text { Atribui valor positivo ao processo eleitoral e à atuação do mesário, compreen- } \\
\text { dendo a participação política e social como dever de todos. Percebe a participa- } \\
\text { ção do mesário como uma experiência gratificante, geradora de "aprendizado } \\
\text { humano", em decorrência da possibilidade de interação com diversas pessoas e } \\
\text { das relações de igualdade que se estabelecem entre todos os envolvidos, no que } \\
\text { se refere aos direitos, deveres, peso do voto, importância do papel desempenha- } \\
\text { do - tanto entre os eleitores, quanto em relação aos mesários. Evidenciou, cons- } \\
\text { ciente e inconscientemente, extrema preocupação com o bem-estar das pessoas } \\
\text { envolvidas no processo de votação - eleitores e demais mesários que atuam na } \\
\text { seção onde trabalha, como bem refletem os trechos a seguir: "É muito interes- } \\
\text { sante estar com uma variedade grande de pessoas ... É bom tratar bem as pesso- } \\
\text { as, com humanidade. O gesto, o sorriso tem um significado grande para todos, } \\
\text { seja eleitor, o mesário, o acompanhante..." (R). "Infelizmente, já vi mesários de } \\
\text { outras seções impacientes, tratando mal os eleitores mais simples..., é o tipo de } \\
\text { coisa que aborrece quem leva a sério esse trabalho" (CI). }\end{array}$ & $\begin{array}{l}\text { - Dever cidadão; } \\
\text { - Colaborar em algo importan- } \\
\text { te para a sociedade; } \\
\text { - Possibilidade de interação; } \\
\text { - Igualdade de todos, inde- } \\
\text { pendente da classe social, } \\
\text { profissão, sexo, etc.; } \\
\text { - Desenvolvimento pessoal. }\end{array}$ \\
\hline
\end{tabular}




\begin{tabular}{|c|c|c|}
\hline $\begin{array}{l}\text { CARLOS } \\
\left(6^{\mathrm{a}} \text { vez como }\right. \\
\text { mesário } \\
\text { voluntário })\end{array}$ & $\begin{array}{l}\text { Demonstra buscar atuação ampla na sociedade, procurando se envolver em ati- } \\
\text { vidades que promovam o debate, tornando-o cada vez mais qualificado e seguro } \\
\text { como cidadão. Como se pode apreender a partir de trechos de sua fala transcri- } \\
\text { tos, como o que se segue, onde o sujeito refere-se às reuniões do sindicato de } \\
\text { que participa: "A gente discute muito, até se exalta às vezes, mas é uma troca né, } \\
\text { uma via de mão dupla. A gente ouve opiniões diferentes das nossas, que fazem } \\
\text { a gente pensar sobre nossa posição e eu acredito que é assim que se evolui, que } \\
\text { se aprende, sozinho não dá para progredir.. e o trabalho do mesário tem um } \\
\text { pouco disso, te dá a chance de discutir politica, democracia, problemas da atu- } \\
\text { alidade, e eu gosto disso, sou carioca e também sou professor!" (CI). Entende, } \\
\text { ainda, que participar do processo eleitoral é cumprir uma obrigação civil, que } \\
\text { deve ser realizada com responsabilidade e estrita observância das normas em } \\
\text { vigor, além de ser também um meio de obter dias extras para descanso e lazer. }\end{array}$ & $\begin{array}{l}\text { - Dever cidadão; } \\
\text { - Aquisição de conhecimen- } \\
\text { tos, através da possibilidade } \\
\text { de interação; } \\
\text { - Obtenção de folgas. }\end{array}$ \\
\hline $\begin{array}{l}\text { OSVALDO } \\
\left(3^{\text {a }} \text { vez como }\right. \\
\text { mesário } \\
\text { voluntário })\end{array}$ & $\begin{array}{l}\text { Solicitou, insistentemente, para ser nomeado, até surgir uma vaga como } 2^{\circ} \text { me- } \\
\text { sário. Ocasião em que manifestou: “... acredito que seria mais adequado e até } \\
\text { proveitoso para a Justiça Eleitoral me colocarem num cargo mais importante, } \\
\text { como o de Presidente de Mesa"(CI). Declarou-se, diversas vezes, agradecido pela } \\
\text { confiança nele depositada e que o amor "à pátria", "ao país”, às pessoas", era o } \\
\text { que o impulsionava ao voluntariado; traduzindo sua nomeação como "... uma ben- } \\
\text { ção" (CF). Criticou aqueles que se voluntariam pensando na obtenção de folgas, } \\
\text { justificando que nunca havia gozado do benefício por exercer função de "supervi- } \\
\text { sor numa empresa" ou "supervisor de uma equipe”, entretanto, um e-mail envia- } \\
\text { do ao Cartório Eleitoral pela síndica do condomínio onde trabalha, questionando } \\
\text { sobre seu direito ao gozo das folgas decorrentes do treinamento, revelou que o } \\
\text { mesmo atuava como Porteiro. Durante a atuação e, indiretamente, no decorrer dos } \\
5 \text { momentos empíricos de que participou como sujeito da pesquisa, demonstrou } \\
\text { extrema necessidade de reconhecimento, prestígio e valorização. Notou-se, ainda, } \\
\text { nítida incoerência entre diversas manifestações formais e ações do sujeito. }\end{array}$ & $\begin{array}{l}\text { - Reconhecimento e valoriza- } \\
\text { ção de sua capacidade; } \\
\text { - Busca de prestígio social; } \\
\text { - Obtenção de folgas. }\end{array}$ \\
\hline $\begin{array}{l}\text { BIANCA } \\
\left(2^{\mathrm{a}} \text { vez como }\right. \\
\text { mesário } \\
\text { voluntário })\end{array}$ & $\begin{array}{l}\text { Voluntariou-se buscando apenas a obtenção de folgas, passando, após vivenciar a } \\
\text { experiência, a atribuir maior valor ao voto e ao processo eleitoral, alterando sua } \\
\text { configuração subjetiva anterior, "É cansativo (o dia da eleição) para o mesário, } \\
\text { mas é válido. Fazendo parte da eleição você acaba valorizando mais a possibili- } \\
\text { dade de escolha que tem ..." (CG). Para ela, ser mesária é algo prazeroso e diverti- } \\
\text { do, que precisa estar inserido num clima agradável para ser bem realizado. }\end{array}$ & $\begin{array}{l}\text { - Obtenção de folgas; } \\
\text { - Prazer/diversão; } \\
\text { - Estar colaborando em algo } \\
\text { importante para a sociedade. }\end{array}$ \\
\hline $\begin{array}{l}\text { RICARDO } \\
\left(1^{\mathrm{a}} \text { vez como }\right. \\
\text { mesário } \\
\text { voluntário })\end{array}$ & $\begin{array}{l}\text { Ser voluntário vai ao encontro de objetivos, projetos e necessidades pessoais de } \\
\text { Ricardo que, iniciando sua vida profissional, buscava "... provar que o jovem } \\
\text { também é capaz de ser responsável" (CI). Referindo-se ao trabalho do mesário } \\
\text { como algo importante e de grande valor para a sociedade, ao mesmo tempo em } \\
\text { que demonstrava evidente empolgação em razão de sua primeira participação, } \\
\text { revelou no encontro grupal: "A minha gerente até me parabenizou, achou bem } \\
\text { legal eu me interessar por essas coisas..." (CG). Demonstrou responsabilidade } \\
\text { em suas ações e ânimo para conquistar novos conhecimentos, aliado ao desejo } \\
\text { de socializar-se e de afirmação pessoal. }\end{array}$ & $\begin{array}{l}\text { - Oportunidade para afirmar- } \\
\text { se responsável e confiável; } \\
\text { - Socialização; } \\
\text { - Aquisição de novas capaci- } \\
\text { dades e conhecimentos. }\end{array}$ \\
\hline $\begin{array}{l}\text { GUSTAVO } \\
\left(4^{\text {a }} \text { vez como }\right. \\
\text { mesário } \\
\text { voluntário })\end{array}$ & $\begin{array}{l}\text { Apenas para adquirir o direito a folgas no serviço; compreende as eleições como } \\
\text { um meio de legitimar a preponderância de pequenos grupos sobre a massa da } \\
\text { população; define o mesário como "... alguém necessário para apertar botões e } \\
\text { entregar os papeizinhos" (R); demonstra-se revoltado com a política, "...., é tan- } \\
\text { ta coisa ruim na politica que não dá vontade de participar nem como eleitor" } \\
(C G) \text {. Entretanto, de forma inconsciente, reconhece a participação do mesário } \\
\text { como um meio dos cidadãos fiscalizarem o processo eleitoral, impedindo frau- } \\
\text { des na votação. Declara que, a partir do momento que se voluntariou, tem o } \\
\text { dever de exercer a função da melhor maneira possível, a pesar de não vê-la como } \\
\text { importante para a sociedade. }\end{array}$ & $\begin{array}{l}\text { - Obtenção de folgas; } \\
\text { - Garantir a legalidade do } \\
\text { processo de votação; } \\
\text { - Obrigação moral. }\end{array}$ \\
\hline $\begin{array}{l}\text { LOURENÇO } \\
\left(1^{\text {a }} \text { vez como }\right. \\
\text { mesário } \\
\text { voluntário })\end{array}$ & $\begin{array}{l}\text { Desde muito jovem sempre foi voluntário, demonstra sentir enorme prazer e bem } \\
\text { estar emocional quando pode ajudar outras pessoas, além de que, para ele, a par- } \\
\text { ticipação voluntária passa a ser um excelente espaço para interação e aquisição de } \\
\text { novos conhecimentos. "Sejam voluntários sempre que surgir uma oportunidade. } \\
\text { É muito bom poder ajudar alguém a sair de uma situação dificil, vocês terão um } \\
\text { retorno enorme, uma bagagem que lhes acompanhará por toda vida, ..." (CG). } \\
\text { Considera as eleições como uma valiosa oportunidade que permite às pessoas in- } \\
\text { dicarem seu futuro, desde que sejam responsáveis e conscientes na hora de votar. }\end{array}$ & $\begin{array}{l}\text { - Obrigação moral; } \\
\text { - Socialização; } \\
\text { - Aquisição e transmissão de } \\
\text { conhecimentos. }\end{array}$ \\
\hline
\end{tabular}




\begin{tabular}{|c|c|c|}
\hline $\begin{array}{l}\text { MARCELO } \\
\left(3^{\mathrm{a}} \text { vez como }\right. \\
\text { mesário } \\
\text { voluntário })\end{array}$ & $\begin{array}{l}\text { Demonstra desânimo e revolta com o “.... baixo nível das eleições no Brasil”" } \\
(C F) \text { e “... a falta de crédito em relação à classe politica." (QD), vale-se dos } \\
\text { momentos desta pesquisa para expor suas opiniões acerca da democracia e da } \\
\text { política brasileira: "A política no Brasil tem que melhorar muito ainda. É muito } \\
\text { fisiologismo, compra de votos, falta de ética de partidos e candidatos ... Toda } \\
\text { eleição dou muitos votos nulos por falta de opção ...” (QD). Percebe sua par- } \\
\text { ticipação nas eleições como um modo de contribuir para a construção de um } \\
\text { futuro melhor e de afiançar a transparência da votação, capaz de gerar, ainda, } \\
\text { economia de dinheiro público (com publicidade e emissão de convocações) e } \\
\text { satisfação pessoal (por ajudar/orientar pessoas e obter novos conhecimentos) } \\
\text { e esclarece: "Minha participação como voluntário nas eleiçóes/2008 não foi } \\
\text { por patriotismo, pois não acredito nos valores da instituição chamada pátria, } \\
\text { principalmente num país onde os que se candidatam a representantes do povo } \\
\text { tradicionalmente pensam somente em si mesmos ...” (R) }\end{array}$ & $\begin{array}{l}\text { - Obrigação - como ser huma- } \\
\text { no e servidor público; } \\
\text { - Aquisição de conhecimen- } \\
\text { tos, através da possibilidade } \\
\text { de interação; } \\
\text { - Transparência da votação; } \\
\text { - Contribuir com algo impor- } \\
\text { tante para a sociedade. }\end{array}$ \\
\hline $\begin{array}{l}\text { ISMAEL } \\
\left(15^{\mathrm{a}} \text { vez como }\right. \\
\text { mesário })\end{array}$ & $\begin{array}{l}\text { Manifesta revolta em relação à política no Brasil, em razão da corrupção e da } \\
\text { impunidade; acredita que a Justiça Eleitoral deveria ser mais rígida no julga- } \\
\text { mento dos processos de registro de candidatura e na fiscalização das campanhas. } \\
\text { Apesar disso, demonstra grande satisfação quando de sua participação como } \\
\text { mesário, valendo-se de sua vasta experiência para auxiliar eleitores, prepostos e } \\
\text { mesários de outras seções, como narra: "Já levei muita gente no colo para votar } \\
\text {... e faço isso com o maior prazer, me sinto feliz em poder ajudar às pessoas" } \\
\text { (CG) e acrescenta, "... sendo o voto obrigatório no Brasil, procuro tornar esse } \\
\text { dever menos penoso possível ..." (R). }\end{array}$ & $\begin{array}{l}\text { - Aquisição e transmissão de } \\
\text { conhecimentos; } \\
\text { - Ser útil às pessoas. }\end{array}$ \\
\hline $\begin{array}{l}\text { FABRÍCIA } \\
\left(1^{\mathrm{a}} \text { vez como }\right. \\
\text { mesária } \\
\text { voluntária })\end{array}$ & $\begin{array}{l}\text { Participante mais jovem, voluntariou-se "para ter mais chances em concursos } \\
\text { e por curiosidade" }(Q D) \text {, ou seja, para obter a declaração do trabalho como } \\
\text { mesária; demonstra pouca esperança em relação à política. Durante o } 1^{\circ} \text { turno } \\
\text { de votação, além de ter se apresentado com atraso de duas horas, esteve pouco } \\
\text { envolvida nos trabalhos da seção, gerando insatisfação nos outros membros. } \\
\text { Não retornou para trabalhar após o almoço e fora substituída para o } 2^{\circ} \text { turno de } \\
\text { votação. }\end{array}$ & $\begin{array}{l}\text { - Meio de obter melhor classi- } \\
\text { ficação em concursos; } \\
\text { - Interesse pessoal (curiosi- } \\
\text { dade) em conhecer melhor } \\
\text { o funcionamento do sistema } \\
\text { eletrônico de votação. }\end{array}$ \\
\hline $\begin{array}{l}\text { JOEL } \\
\left(3^{\mathrm{a}} \text { vez como }\right. \\
\text { mesário } \\
\text { voluntário })\end{array}$ & $\begin{array}{l}\text { Acredita ser possível, por meio de sua atuação como mesário, transformar as vi- } \\
\text { sões das pessoas a respeito do processo eleitoral “... repassar meu conhecimento } \\
\text { democrático aos eleitores e aos outros mesários e isso me fortalece no meu co- } \\
\text { nhecimento de democracia”" (QD). Manifestando, ainda, que Preside sua seção } \\
\text { de acordo com suas ideias, mesmo que estas discordem da legislação eleitoral, } \\
\text { e não aceitando o fato de que sua posição como Presidente de seção não lhe } \\
\text { garanta tal autonomia, justificando: "Nosso povo ainda é muito ignorante, troca } \\
\text { o voto por qualquer migalha e a lei faz de tudo para facilitar essas coisas, man- } \\
\text { dam não exigir documento com foto, deixar levar acompanhante para dentro da } \\
\text { seção, analfabeto votar e até ser candidato!...” (CG). Participou dos encontros e } \\
\text { conversações relativas a esta pesquisa e do treinamento da Justiça Eleitoral, mas } \\
\text { não compareceu para trabalhar como mesário nas eleições. }\end{array}$ & $\begin{array}{l}\text { - Transmissão de ideias e } \\
\text { conhecimentos; } \\
\text { - Conduzir o processo de vo- } \\
\text { tação na sua seção de modo } \\
\text { coerente com suas opiniões; } \\
\text { - Busca por valorização e } \\
\text { reconhecimento. }\end{array}$ \\
\hline
\end{tabular}

Fonte: Elaborado pelas autoras.

Observa-se que, a partir das informações empíricas, foram revelados sentidos subjetivos bastante variados, destacando o quanto uma atividade altamente normatizada, padronizada e, podemos dizer até, cronometrada, como é o trabalho exercido pelos mesários durante as eleições, abre espaço para uma produção de sentidos tão rica, diferenciada e sensível às particularidades de cada sujeito. Tal fato ratifica a posição de González Rey (2002, 2003, 2004, 2005), de que não existem formas universais de subjetivação de uma atividade.

Diante dessa constatação, propõe-se, a seguir, uma análise articulando diferentes ângulos das informações obtidas, vislumbrando os possíveis processos subjeti- vos que deram origem a comportamentos e embasaram situações envolvendo os mesários abordados. Busca-se, assim, uma melhor compreensão acerca dos fatores que podem estar contribuindo para a ocorrência de problemas provocados por ações inadequadas dos mesários durante as eleições, bem como para as demonstrações de comprometimento com o bom resultado dos trabalhos.

\section{Relacionando sentidos e resultados da participação dos mesários voluntários}

Tendo como referência as situações inadequadas ocorridas durante as eleições 2008, especialmente aque- 
las que guardaram relação com os sujeitos participantes da pesquisa que gerou este artigo, realiza-se, a seguir, uma análise específica de cada uma delas, apresentando os problemas e as possíveis relações com os sentidos subjetivos apurados.

\section{a) Falta de mesários:}

Observa-se a ocorrência deste problema em relação a dois sujeitos desta pesquisa, Fabrícia e Joel. No que diz respeito à Fabrícia, a análise acerca dos sentidos subjetivos de sua participação aponta sua insatisfação em relação ao trabalho desempenhado como mesária, sobretudo por não sentir-se atraída pela interação com os eleitores, aliado a completa descrença em relação ao valor das eleições para a produção de melhorias sociais e pouco interesse em assuntos relacionados à política $\mathrm{e}$ à democracia. Os sentidos subjetivos desvelados para sua participação como mesária dirigem-se apenas à concretização de interesses particulares, os quais se mostraram insuficientes para estimulá-la à realização de um trabalho comprometido, bem como a continuar participando como mesária voluntária.

Em relação ao mesário Joel, nota-se tanto em suas declarações formais, quanto em seu comportamento durante os treinamentos e as eleições anteriores (2006), sua insatisfação com alguns aspectos da legislação que regulamenta os trabalhos dos mesários. Fato que gerou o registro de várias reclamações no pleito de 2006, em razão de ter impedido o voto dos eleitores que se dirigiram à seção portando apenas o título eleitoral, o que era permitido por lei. Assim, percebe-se sua ausência às eleições como decorrente da frustração de sua pretensão de insubordinar-se às regras prescritas pela Justiça Eleitoral e gerir a seção por ele presidida de acordo, apenas, com sua opinião, o que não mais seria aceito pelos demais mesários da sua seção, nem pelos eleitores anteriormente prejudicados.

\section{b) Reclamações registradas no cartório sobre o comportamento de mesários:}

Dentre as 75 reclamações de eleitores registradas nos dois turnos das eleições de 2008, apenas uma relaciona-se à má atuação de participante da pesquisa, no caso Osvaldo, que, ao chegar atrasado para assumir sua função, recebeu uma crítica da Presidente de mesa que o questionou se ele havia chegado "cedo" para o encerramento da votação. Mostrando-se aborrecido, retirou o disquete da urna, como se a votação estivesse realmente chegado ao fim, gerando indignação nos demais membros da seção e atrasando o início da votação. Percebe-se que tal ocorrência somente se concretizou pela ausência de motivos que fossem capazes de compensar a frustração que Osvaldo sentira, uma vez que foram suprimidos, ao mesmo tempo, os dois principais sentidos subjetivos que esse sujeito atribuía à sua participação como mesário voluntário: reconhecimento/ valorização de sua capacidade e responsabilidade; status/prestígio social.

Entretanto, ressaltam-se outras situações motivadoras de reclamações também estiveram presentes em seções das quais participavam sujeitos da pesquisa. Porém, devido às habilidades e interesses particulares demonstrados por esses sujeitos, não geraram insatisfação nos eleitores que as vivenciaram, conforme se passa a relatar.

Houve três reclamações registradas por eleitores sobre a forma como foram tratados por mesários de seções que, tal qual a seção presidida pela participante Tereza, foram transferidas de local (escola) entre os dois turnos de votação. Assim, percebe-se a falta de habilidades interpessoais, ou talvez de interesse e boa vontade desses mesários que, como Tereza, deveriam ter sido mais diligentes e atenciosos no trato com o público, evitando atritos durante o exercício da função. Ressalta-se que a qualidade das ações e o comportamento equilibrado de Tereza durante todo o processo de votação parecem decorrer da trama de sentidos positivos que se entrelaçam na configuração subjetiva de sua participação, especialmente, dos sentidos subjetivos relacionados ao prazer sentido no diálogo e nas relações de troca com os eleitores.

\section{c) Permissão de "boca de urna" e outros tipos de influência de candidato ou partido na seção:}

Uma queixa frequente em eleições, especialmente nas municipais, diz respeito à intromissão de candidatos e fiscais de partido no interior das seções, o que para muitos eleitores indica que os mesários não estão zelando de forma adequada pela legalidade do processo de votação. Nesse aspecto foi presenciada uma discussão entre Gustavo e um fiscal de partido que, com a anuência de outro mesário da seção e ignorando a legislação eleitoral, tentava acompanhar um eleitor idoso durante o exercício do voto, o que não é permitido por lei. Considerando que o eleitor em questão não demonstrou resistência ao assédio do fiscal, pode-se afirmar que tal ilicitude somente não se concretizou devido à reação de Gustavo enquanto Presidente da seção, que se posicionou energicamente, não admitindo sua ocorrência. Compreende-se que a reação do referido mesário encontra respaldo em dois núcleos de sentido subjetivo que foram apreendidos anteriormente, quais sejam: garantir a legalidade do processo de votação e obrigação moral de atuar bem como mesário.

Prosseguindo essa reflexão, percebe-se em sujeitos que apresentam desempenho satisfatório para a 
Justiça Eleitoral, sentidos subjetivos que promovem atitudes de responsabilidade, comprometimento e/ou altruísmo que não estão apenas relacionados à participação no processo eleitoral, mas que funcionam, de acordo com González Rey (2003), como tendências orientadoras de suas personalidades.

Assim sendo, entende-se que fatores como esses, ao serem compreendidos como núcleos de sentido subjetivo mais estáveis do que aqueles relacionados unicamente a uma experiência específica, possuem capacidade de influenciar, ainda mais fortemente, as escolhas e ações do sujeito, na direção de manterem-se coerentes com sua personalidade, como ocorrido com os voluntários Tereza, Gustavo e Lourenço.

Desse modo, vale ressaltar que a proposição anterior também é válida para mesários que promovem ações inadequadas durante os trabalhos eleitorais, como Osvaldo, cujo sentido de reconhecimento e valorização de suas capacidades parece ir além de sua participação como mesário, implicando atitudes de desrespeito às normas e falta de comprometimento com os resultados a serem alcançados pela seção, como demonstrado por Osvaldo no $2^{\circ}$ turno das eleições.

Nota-se, ainda, que todos os sujeitos desta pesquisa que atribuíram o sentido de dever/obrigação à sua participação nas eleições deram nítidas demonstrações de comprometimento com a realização de um trabalho sério e eficiente. Porém, cabe evidenciar que o sentido dado pelos participantes ao termo "obrigação" não foi sempre o mesmo, sendo empregado de duas maneiras específicas:

- $\quad$ Obrigação social - quando a participação como mesário voluntário é compreendida como uma obrigação decorrente da posição de cidadão perante a sociedade, pela qual também é responsável, devendo contribuir para sua manutenção e melhoria;

- $\quad$ Obrigação moral - decorrente de valores morais e éticos presentes em sua subjetividade, que o fazem acreditar que um mesário voluntário tem a obrigação moral de realizar um bom trabalho.

Como exemplo dessa proposição, pode-se citar a participação dos mesários Tereza e Gustavo, que demonstraram excelente desempenho nos dois turnos das eleições, apesar de perceberem-na dotada de sentidos bastante diferenciados, tendo como única semelhança concebê-la como uma obrigação social para Tereza e para moral para Gustavo.

Observa-se, além disso, que quando esse sentido de obrigação (seja ela moral ou social) figura entrelaçado a outros sentidos subjetivos que denotam interesse e satisfação pessoal pelo envolvimento na atividade, os voluntários demonstraram forte desejo de permanecer colaborando, o que parece os ter impulsionado a exercer a função com extrema dedicação, a fim de que todos os objetivos da Justiça Eleitoral fossem alcançados com excelência e, assim, mantenham-se como mesários. É o que indica o resultado da atuação dos participantes Lourenço, Marcelo, Bianca, Tereza e Carlos, que além do sentido de obrigação, imputam às suas participações sentidos subjetivos relacionados a interesses pessoais, como socialização, interação, diversão e aquisição de conhecimentos e de folgas.

\section{Considerações finais}

Buscou-se, por meio da análise dos sentidos subjetivos da participação do mesário voluntário, a construção de um conhecimento que contribuísse para a compreensão dos fatores que poderiam estar colaborando para a ocorrência de ações inadequadas de mesários durante as eleições, bem como para o aprimoramento das práticas de gestão da Justiça Eleitoral envolvidas no processo de votação.

Por meio de um processo de análise contínuo, recursivo e multiforme, baseado no diálogo, interpretação e construção, articulando os núcleos de sentido subjetivo apurados e os resultados visíveis da participação dos sujeitos durante as eleições, sem desconsiderar o contexto histórico, político, social e institucional em que se dá essa atuação, pôde-se apreender que os comportamentos incompatíveis com a função alimentam-se dos sentidos subjetivos que o voluntário relaciona ou constrói sobre e a partir de sua participação como mesário ou, ainda, da frustração desses sentidos, como observado em relação aos participantes Fabrícia, Osvaldo e Joel.

No mesmo caminho, compreende-se que só há comprometimento do mesário com a qualidade dos serviços realizados se os sentidos subjetivos que este atribui e/ou relaciona à sua participação voluntária no processo eleitoral favorecerem comportamentos nessa direção. Entretanto, é importante ressaltar, tais sentidos podem não estar vinculados unicamente à experiência da participação como mesário voluntário, sendo procedentes de outros momentos por ele já vivenciados ou, ainda, estando presentes de forma estável na configuração subjetiva de sua personalidade, porém exercendo influência direta sobre as posições tomadas no seu momento atual.

Assim, esta pesquisa contribui para o estudo da participação voluntária, ao demonstrar que não basta um sujeito possuir qualificação suficiente e dispor-se voluntariamente a participar de um projeto ou ação, para que o resultado de sua atuação seja satisfatório a quem dela irá valer-se, seja eleitor, Justiça Eleitoral ou qualquer outro beneficiário/organização. $\mathrm{O}$ fato de 
voluntariar-se não implica necessariamente valores, necessidades, percepções e sentimentos compatíveis com atitudes de comprometimento e voltadas à qualidade dos serviços prestados pelo voluntário, os quais derivam, efetivamente, da integração dos sentidos subjetivos que estejam envolvidos no processo de ação concreta desse sujeito.

No que se refere às práticas de gestão dos mesários voluntários empregadas na organização e condução do processo de votação no cartório pesquisado, os resultados desta pesquisa apontam necessidades e adequações, que vão desde o desenvolvimento e implantação de um processo de seleção eficiente, passando por uma maior aproximação entre Justiça Eleitoral, mesários e comunidades, incluindo uma reformulação dos treinamentos e um maior acompanhamento das atividades dos mesários nas eleições, a fim de possibilitar o reconhecimento e a valorização dessa participação.

Nota-se, ainda, que a campanha institucional realizada pelo TRE/ES durante o ano de 2008, bem como pelo cartório eleitoral pesquisado, enfatizava as vantagens pessoais que se pode obter através da participação no processo eleitoral, indicando que paira sobre a instituição a representação de que um eleitor só irá sentir-se motivado a voluntariar-se como mesário se tiver a oportunidade de, através de sua participação, obter benefícios particulares. Dessa forma, a campanha coloca as vantagens pessoais como principais produtoras de sentido subjetivo para essa forma de participação voluntária, em detrimento de outros sentidos possíveis, não contribuindo para que pessoas com interesses diversos, tais como colaborar para a mudança social, desenvolvimento da democracia representativa, aprendizado, interação, socialização, ajudar pessoas, fiscalização do processo de votação, etc., sejam estimuladas a participar.

Essa observação serve também como sugestão para novas pesquisas, na medida em que as representações da organização exercem extrema influência sobre a percepção dos voluntários acerca da relevância do trabalho realizado, alcançando, ao mesmo tempo, a produção subjetiva desses diante do contexto instituído.

No que diz respeito às limitações deste estudo, pode-se apontar que, provavelmente, não foi abarcar os inúmeros sentidos subjetivos que são produzidos e evocados diante da participação voluntária dos mesários nas eleições. Ainda, nossa incapacidade, dada a complexidade do método de pesquisa adotado, para apreender todos os sentidos subjetivos envolvidos na configuração subjetiva da ação dos sujeitos pesquisados, reconhecendo que para tanto seria necessária uma investigação ainda mais profunda e com mais tempo para a realização da pesquisa, especialmente a respeito da história de vida de cada um deles.
Entretanto, considera-se que tais limitações não comprometem a capacidade deste estudo em dar visibilidade à inter-relação existente entre os sentidos subjetivos e as ações dos mesários, suscitando um novo olhar sobre a participação de voluntários no âmbito da Justiça Eleitoral brasileira. Demonstra, ainda, a incontestável pertinência da Teoria Histórico-Cultural da Subjetividade na aproximação de objetos relacionados à gestão de pessoas, como citam Paula \& Palassi (2007), ao dizer que a organização não é apenas um espaço de controle da subjetividade, mas, principalmente, palco de produção de subjetividades.

\section{Referências}

Acioli, V. L. C. (1997). Jurisdição constitucional: aspectos da administração colonial. Recife: UFPE.

Amaral, A. L. S. N. (2006). O sentido subjetivo da aprendizagem para alunos universitários criativos. Dissertação de Mestrado, Programa de Mestrado em Educação, Universidade Federal de Brasília, Brasília, DF.

Bock, A. M. B. \& Gonçalves, M. G. M. (2005). Subjetividade: o sujeito e a dimensão subjetiva dos fatos. In F. L. G. González Rey (Org.), Subjetividade, complexidade e pesquisa em psicologia (pp. 109-125). São Paulo: Thomson Learning.

Bordenave, J. E. D. (1994). O que é participação? São Paulo: Brasiliense.

Carvalho, J. M. (2006). Cidadania no Brasil: o longo caminho ( $8^{\text {a }}$ ed.). Rio de Janeiro: Civilização Brasileira.

Demo, P. (1993). Participação é conquista. São Paulo: Cortez.

Dias, R. A. M. \& Palassi, M. P. (2007). Produção científica sobre o voluntariado: uma análise a partir dos artigos publicados nos principais eventos e revistas nacionais de administração. In Anais da Conferência Regional de ISTR para América Latina e El Caribe (pp. 1-16). Salvador, BA.

Furtado, O. (2002). As dimensões subjetivas da realidade. In F. L. González Rey \& O. Furtado (Orgs.), Por uma epistemologia da subjetividade: um debate entre a teoria sócio-histórica e a teoria das representações sociais (pp. 91-105). São Paulo: Casa do Psicólogo.

Garay, A. B. B. S. (2001). Programa de voluntariado empresarial: modismo ou elemento estratégico para as organizações? Revista de Administração, 36(3), 6-14.

González Rey, F. L. (1997). Epistemologia cualitativa y subjetividad. São Paulo: EDUC.

González Rey, F. L. (1999). La investigación cualitativa em Psicología: rumbos y desafios. São Paulo: Educ.

González Rey, F. L. (2002). Pesquisa qualitativa em psicologia. São Paulo: Thomson Learning.

González Rey, F. L. (2003). Sujeito e subjetividade. São Paulo: Pioneira Thomson Learning.

González Rey, F. L. (2004). O social na psicologia e a psicologia social. Petrópolis, RJ: Vozes.

González Rey, F. L. (2005). Pesquisa qualitativa e subjetividade. São Paulo: Thomson Learning.

Iasulaitis, S. \& Silva, E. C. (2006). Descentralização do processo decisório por meio da participação popular. In Colóquio Internacional sobre Poder Local, 10. Anais (pp. 1-10). Salvador, BA. 
Instituto Antônio Houaiss. (2001). Dicionário eletrônico Houaiss da lingua portuguesa [CD-ROM]. Rio de Janeiro: Objetiva.

Leal, V. N. (1997). Coronelismo, enxada e voto: o municipio e o regime representativo no Brasil ( $3^{\text {a }}$ ed.) Rio de Janeiro: Nova Fronteira.

Lima, M. M. A. B. (2005). A democracia da atualidade e seus limites: o financiamento público de campanhas eleitorais. Mundo Jurídico (pp. 1-24). Acesso em 23 de setembro, 2008, em www.mundojuridico.adv.br/cgi-bin/upload/texto907.rtf

Martínez, A. M. (2005). A teoria da subjetividade de Gonzalez Rey: uma expressão do paradigma da complexidade. In F. L. Gonzalez Rey (Org.), Subjetividade, complexidade e pesquisa em psicologia (pp. 1-25). São Paulo: Pioneira Thomson Learning.

Martínez, A. M. \& Simão, L. M. (2004). O outro no desenvolvimento humano: diálogos para a pesquisa e a prática profissional em psicologia. São Paulo: Thomson Learning.

Mascarenhas, A. O. \& Zambaldi, F. (2002). Motivação em programas de voluntariado empresarial: um estudo de caso. In ENANPAD. Anais (pp. 1-14). Rio de Janeiro, RJ.

Nicolau, J. (2004). Participação eleitoral: evidências sobre o caso brasileiro. In Congresso Luso-Afro-Brasileiro de Ciências Sociais, 7 (pp. 1-24). Coimbra. Acesso em 3 de junho, 2008, em http://www.ces.fe.uc.pt/lab2004/pdfs/JairoNicolau.pdf

Paula, A. P. P. \& Palassi, M. P. (2007). Subjetividade e simbolismo nos estudos organizacionais: um enfoque histórico-cultural. In A. P. Carrieri \& L. A. S. Saraiva (Orgs.), Simbolismo organizacional no Brasil (pp. 199-228). São Paulo, SP: Atlas.

Sabucedo, J. M. (1996). Psicología política. Madrid: Síntesis.

Sadek, M. T. A. (1995). A justiça eleitoral e a consolidação da democracia no Brasil. São Paulo: Fundação KonradAdenauer-Stiftung.

Shimizu, A. M. \& Menin, M. S. S. (2004). Representações sociais de lei, justiça e injustiça. Estudos de Psicologia, 9(2), 239-247.

Souza, W. J., Fernandes, C. L. M., \& Medeiros, J. P. (2006). Trabalho Voluntário. In Colóquio Internacional sobre Poder Local, 10. Anais (pp. 1-10). Salvador, BA.

Speck, B. W. (2003). A compra de votos. Opinião Pública, 9(1), 148-169.

Teodósio, A. S. S., Veneroso, R. S., \& Pena, R. P. M. (2006). Nada de novo no front. In S. M. Pimenta, L. A. S. Saraiva, \& M. L. Corrêa (Orgs.), Terceiro setor: dilemas e polêmicas. (pp. 19-40). São Paulo: Saraiva.
Tribunal Superior Eleitoral. (2008). Código eleitoral anotado e legislação complementar. Brasília, DF: Autor.

Valente Neto, J. (2004). A evolução político-eleitoral do Brasil. Pensar, 9(9), 82-88.

Vasconcellos, J. G. M. (1995). A invenção do coronel. Vitória: Edufes.

Vervloet, A. M. P. (2008). Representações sociais da atuação do mesário nas eleições: uma análise comparativa entre mesários voluntários e convocados. In Encontro de Estudos Organizacionais, 5. Anais (pp. 1-16). Belo Horizonte, MG.

Recebido em: 18/08/2009

Revisão em: 14/06/2010

Aceite final em: 18/11/2010

Aigline de Menezes Paes Vervloet é Mestre em Administração pela Universidade Federal do Espírito Santo (UFES) e Professora do Departamento de Administração da UFES.

Endereço: Av. Fernando Ferrari, 514. Goiabeiras. Vitória/ ES, Brasil. CEP 29075-910. Email: aigline@terra.com.br

Márcia Prezotti Palassi é Doutora em Psicologia Social pela PUC/SP e Professora do Programa de Pós-Graduação em Administração e do Programa de Pós-Graduação em

Ciências Sociais da Universidade Federal do Espírito Santo (UFES). Email: mprezotti@hotmail.com

\section{Como citar:}

Vervloet, A. M. P. \& Palassi, M. P. (2011). Eleições, mesários e subjetividade: reflexões sobre a produção de sentidos subjetivos a partir da participação voluntária no processo de votação. Psicologia \& Sociedade, 23(2), 312-324. 